\title{
Políticas culturais e hierarquias SIMBÓlICAS NO CAMPO DO TEATRO PAULISTANO: AS LUTAS PELA LEI DE FOMENTO
}

Simone do Prado ROMEO*

\begin{abstract}
RESUMO: Este artigo debate a trajetória do movimento Arte contra a Barbárie, desde sua gênese até sua conquista mais notória: a Lei de Fomento ao Teatro para a Cidade de São Paulo, que constitui uma inovação no panorama das políticas públicas no contexto brasileiro. Ao iluminar esse percurso, buscamos evidenciar as estratégias de legitimação cultural de que o movimento lançou mão, bem como os condicionantes que concorreram para tornar possível tal conquista.
\end{abstract}

PALAVAS-CHAVE: Teatro. Políticas culturais. Hierarquias simbólicas. Legitimidade cultural.

Para os amantes das artes da cena, o panorama teatral recente da cidade de São Paulo tem sido motivo de atenção. Seja por conta da proliferação significativa de coletivos teatrais que despontaram na cena local providos de disposição política, vontade crítica e invenção artística; seja, ainda, pelo fato inédito de tais coletivos terem logrado impor as categorias de percepção e apreciação teatrais legítimas através de uma lei de fomento público, em vigor na capital paulista desde 2002. Trata-se da conhecida Lei de Fomento ao Teatro para a cidade de São Paulo (SÃO PAULO, 2002) que instituiu o principal programa público de apoio ao teatro de que se tem notícia no Brasil, tornando-se marco para as políticas públicas de cultura e modelo de política cultural mais independente das injunções de mercado ${ }^{1}$. Atento

USP - Universidade de São Paulo. Escola de Comunicações e Artes. Doutoranda do Programa de Pós-graduação em Artes Cênicas. Departamento de Artes Cênicas. São Paulo - SP - Brasil. 05508-020 simoneromeo@usp.br. https://orcid.org/0000-0003-4535-5860.

1 Daqui por diante, iremos nos referir a ela apenas por Lei de Fomento, maneira como é comumente conhecida. 
a esse cenário, o presente artigo propõe uma análise do Arte contra a Barbárie, movimento político-cultural que deu origem à referida Lei, iluminando sua trajetória entre os anos de 1998 a 2002, interrogando sobre as espécies de capital e as condições extra artísticas que tornaram possíveis essa conquista singular no contexto das políticas culturais brasileiras. Dito de outra forma, o interesse em abordar a trajetória do referido movimento está em compreender a maneira pela qual uma fração do campo teatral paulistano - dominada do ponto de vista econômico se lançou ao desafio de legitimar simbolicamente o teatro que produz, a ponto de ele ser reconhecido pela municipalidade como digno de receber financiamento público direto, na contramão das políticas culturais em voga orientadas, estas, pelo patrocínio empresarial por via dos incentivos fiscais.

Admitindo a dupla natureza dos bens simbólicos, partimos da oposição entre um teatro comercial e um teatro de pesquisa (BOURDIEU, 2014) para compreender as lutas que culminaram com a elaboração e posterior aprovação da Lei de Fomento. De acordo com as proposições de Pierre Bourdieu, a revolução simbólica na qual os artistas modernos afirmaram o princípio da autonomia da arte fundou nesse campo de produção, a lógica de uma economia antieconômica na qual a invenção de uma estética pura instituiu nesse universo uma estrutura dualista, que corresponde a dois modos de produção e circulação obedecendo a lógicas distintas. (BOURDIEU, 1996). Num dos polos temos uma produção heterônoma que, fazendo da criação artística uma produção como outra qualquer, orienta-se pela busca do lucro e do sucesso econômico, direcionando a produção de bens simbólicos para a satisfazer a uma demanda preexistente e que, fundada num ciclo curto de produção, dá forma à uma arte comercial (BOURDIEU, 2014). No polo oposto encontra-se uma produção que, não reconhecendo outra demanda senão a que a própria arte é capaz de produzir, funda-se sobre o princípio da autonomia estética e, consequentemente, da aceitação do risco inerente à produção artística, que é estranha à lógica ordinária da economia ordinária e que repousa, portanto, na denegação do lucro econômico. Instaura-se, assim, uma realidade na qual "o artista só pode triunfar no terreno simbólico perdendo no terreno econômico (pelo menos a curto prazo) e inversamente (pelo menos a longo prazo)" (BOURDIEU, 1996, p.105). Tal oposição figura como um princípio gerador da maior parte dos julgamentos sobre o que é arte e o que não é, dando ensejo às lutas entre a ortodoxia e a heresia, que refletem conflitos estéticos sobre a visão de mundo legítima, sobre aquilo que merece ser representado e a maneira correta de fazer a representação. Se é assim, podemos observar que as lutas que culminaram com a Lei de Fomento, bem como os procedimentos de trabalho e os critérios de julgamento que ela fixa, produziram uma série de rupturas com relação à ortodoxia teatral.

Conforme constatamos em estudo precedente (ROMEO, 2016), as lutas que culminaram com a elaboração e posterior aprovação da Lei de Fomento impactaram 


\section{Politicas culturais e hierarquias simbólicas no campo do teatro paulistano: as lutas pela lei de fomento}

todo o campo de produção, gerando deslocamentos com relação aos parâmetros vigentes no que tange ao teatro digno de ser admirado e financiado com verbas estatais. O exame desse movimento recente do teatro paulistano e das transgressões simbólicas que ele foi capaz de produzir demonstrou também a ordem de questionamentos a partir da qual ele se constituiu, os termos em torno dos quais sua pauta foi se estruturando e suas estratégias de legitimação cultural, evidenciando, assim, as percepções artísticas em disputa.

A verificação do processo de formulação e posterior aprovação dessa política cultural foi construída com base em diversas fontes documentais e empíricas, tais como materiais de arquivo ${ }^{2}$; documentos públicos, como textos-manifestos, a própria Lei de Fomento e entrevistas semi-diretivas com artistas participantes do movimento, especialmente os diretores teatrais. Procedemos, ainda, ao levantamento e análise dos trabalhos que abordam a Lei de Fomento ou o movimento que lhe deu origem, buscando dialogar com o que foi produzido sobre o tema. Sobre isso, importa destacar que a falta de estudos acadêmicos sobre o assunto ou a tendência corrente em abordar a Lei de Fomento como algo ex-nihlo constituíram as motivações primordiais da análise aqui proposta.

\section{Por um novo modo de produção teatral}

Contrariando a tese de vazio cultural ${ }^{3}$ que marcou a crítica teatral brasileira a partir dos anos 1980, a recente virada de século na cidade de São foi marcada pelo surgimento de um número expressivo de coletivos teatrais, conhecidos por teatro de grupo, responsáveis por conformar um novo padrão de trabalho artístico chamados de processo colaborativo. Trata-se de um modo de organização do trabalho teatral que, a nosso ver, realiza uma espécie de síntese nova dos avanços cênicos colocados em curso pelas vanguardas dos decênios anteriores. Inspirado nos princípios da criação coletiva, típica dos coletivos de 1970; nos avanços introduzidos pelos grandes encenadores brasileiros de 19804; e, ainda, no conceito de ator-criador, temos um modo de criação que, em linhas gerais, defende a horizontalidade nas relações entre os criadores do espetáculo teatral e traz as marcas da improvisação,

\footnotetext{
2 Acervo do movimento Arte contra a Barbárie, em posse do Arquivo Multimeios do Centro Cultural São Paulo (CCSP). À época da consulta, tais materiais não estavam tombados nem catalogados, impedindo a referência precisa. Por isso, utilizaremos o título original e a data contida no próprio documento, quando houver.

3 Que seria resultado tanto da onda de repressão e censura levadas a cabo pela ditadura civil-militar que se instalou no país de 1964-1985, quanto das transformações denunciadas a partir da invasão do mercado por produções estrangeiras, principalmente aquelas ligadas ao show business (COSTA, 1996) 4 Nos referimos fundamentalmente à tríade de diretores composta por José Celso Martinez Corrêa, Antunes Filho e Gerald Thomas.
} 
da performatividade, da pesquisa, do inacabamento e da intervenção do público no processo criativo (DESGRANGES, 2012). Com efeito, partindo do princípio de que o modo como se organizam as relações de produção impacta no processo criativo e nos próprios resultados da obra, temos então uma produção em diacronia com o teatro comercial ganhando corpo na cena local e que se pretende, portanto, mais independente com relação ao mercado de patrocínios culturais. Contudo, considerando que para realizar uma produção artística de qualquer natureza o produtor precisa acessar determinados recursos materiais, esses artistas terão por desafio encontrar formas alternativas de subvenção.

\section{Arte e políticas públicas no Brasil}

Se a relação entre Estado e cultura é milenar, é contemporâneo o olhar do Estado sobre a cultura como uma área que deve ser tratada sob a ótica das políticas públicas, com seu caráter normativo e ordenador (CALABRE, 2009). No caso brasileiro, perpassando a história das políticas culturais, temos uma trajetória que, além de seu caráter tardio, é marcada pelo autoritarismo, descontinuidade e fragilidade institucional (RUBIM; BAYARDO, 2008, p.32).

Caráter tardio porque, de acordo com a historiografia sobre o tema, é somente partir da Era Vargas (1930-1945) que se pode falar em política cultural no Brasil. Período no qual se observa a primeira construção institucional da área através do esforço daquele estadista em constituir e definir o domínio da cultura como negócio oficial, implicando um orçamento próprio, a criação de uma intellighenzia e a intervenção de todos os setores de produção, difusão e conservação do trabalho intelectual e artístico, conforme demonstrou Sergio Miceli (1979) em seu estudo pioneiro. Com intervalo de algumas décadas, marcadas, estas, por uma fraca presença do Estado e pelo protagonismo da fração mais moderna da burguesia industrial na promoção de cultura (ARRUDA, 2015), o segundo momento de construção institucional da área cultural ocorreu somente durante a ditadura militar (19641985), sobretudo nos anos 1970, momento de reorganização e ampliação do quadro até então existente, com vistas a criar uma política nacional de cultura. Decorre daí uma característica aparentemente paradoxal na história de nossas políticas culturais, já que os dois momentos fundamentais de sua institucionalização aconteceram em regimes autoritários nos quais, não obstante as diversas formas de cerceamento e dirigismo, o Estado foi considerado o grande patrocinador das artes. O que, no caso do teatro, se deu fundamentalmente por via do Serviço Nacional de Teatro (SNT), criado por Vargas e posteriormente reformulado pelos militares. Saíam do SNT os principais editais para produção e circulação de peças ou de prêmios para o teatro nacional. 


\section{Politicas culturais e hierarquias simbólicas no campo do teatro paulistano: as lutas pela lei de fomento}

Contudo, o protagonismo estatal no financiamento às artes iria se alterar drasticamente a partir do governo de transição democrática de José Sarney (19851990). Se, por um lado, tivemos nesse período a criação do Ministério da Cultura (MinC) e de dois artigos na Constituição Federal de 1988 dedicados à área $^{5}$, na prática tal construção se mostrou bastante frágil. Do ponto de vista do MinC, ele foi marcado por grande instabilidade nesses anos, conforme atesta a troca constante dos responsáveis pela pasta ${ }^{6}$, resultando em descontinuidade de projetos e pesquisas no setor (CALABRE, 2009). Por outro lado, não obstante os avanços contidos naqueles artigos, responsabilizando o Estado com relação à cultura, data do mesmo período a primeira iniciativa com vistas a estimular a intervenção corporativa na área cultural, em detrimento do protagonismo do Estado sobre as questões culturais. Nos referimos à criação da LEI No 7.505/86, conhecida como Lei Sarney (BRASIL, 1986), a partir da qual as empresas podiam financiar produções artísticas e aportar recursos usando a renúncia fiscal do imposto sobre a renda. Corroborando a fragilidade e a instabilidade do setor, no governo seguinte (Collor, 1990-1992) o MinC foi extinto e, com ele, a Lei Sarney, sob o argumento de diminuição do gasto público. Mas, condizente com o ideário que defende as políticas de austeridade, no ano seguinte foi promulgada a LEI No 8.313, conhecida por Lei Rouanet (BRASIL, 1991), que surge como uma espécie de aprimoramento daquela e que iria se transformar em modelo para as políticas culturais no país.

Diante de tal quadro, passou a ser debatido senão a institucionalização, mas o desmonte na área cultural, que iria se aprofundar ainda mais sob o governo de Fernando Henrique Cardoso (FHC, 1994-2002), período no qual a Lei Rouanet se converteu em carro-chefe das políticas culturais no país. À época o ministro da cultura, Francisco Weffort (2010, p.3), defendia abertamente que: "O melhor para a política cultural é tentar aprimorar a renúncia fiscal e os fundos". Tal situação promoveu uma série de iniciativas privadas na área da cultura, ao mesmo tempo que retirou o Estado do cenário decisório e da condução do processo (CERQUEIRA, 2018).

De maneira simplificada, as leis de incentivo fiscal consistem no mecanismo através do qual o Estado concede isenção ao pagamento de impostos às empresas patrocinadoras de produções artísticas. A contradição fundamental engendrada por esse mecanismo é que, a despeito de se tratar de dinheiro público - que de outro jeito seria pago na forma de impostos - a decisão sobre o que merece ser financiado fica a critério das empresas, que julgam os projetos artísticos de acordo com seus

\footnotetext{
5 Trata-se dos Art. 215 e 216. O primeiro abre a Seção II "Da cultura", onde lê-se que "O Estado garantirá a todos o pleno exercício dos direitos culturais (...)"enquanto que o segundo é quase que exclusivamente dedicado à preservação do patrimônio, material e imaterial.

6 Apenas durante o governo Sarney; foram cinco os ministros que alternaram no comando da pasta, quais sejam: José Aparecido de Oliveira, Aluísio Pimenta, Celso Furtado Hugo Napoleão do Rego Neto e, novamente, José Aparecido de Oliveira.
} 
interesses corporativos. Sob essa lógica, a arte contemporânea funcionaria como moeda de valor simbólico e material para as corporações. Adentramos, assim, na era do marketing cultural, no qual os grandes bancos e as empresas transnacionais expandem seus negócios para o campo das artes e da cultura como forma de distinção social, da qual depende sua condição dominante e suas aspirações de classe (WOO, 2006).

Entretanto, a contestação desse mecanismo tem sido grande, principalmente por parte das frações da produção cultural que possuem maior dificuldade em estabelecer alianças com a lógica mercantil, sendo que o centro da crítica a esse tipo de política consiste na denúncia de que elas configuram uma forma de subordinação do campo cultural ao campo econômico. Seguindo essa argumentação, as leis de incentivo fiscal terminariam por criar uma nova forma de censura, a censura de mercado.

\section{O teatro contra o mercado}

Com a ampliação da política de incentivos fiscais e a consequente redução dos editais públicos de financiamento direto às artes, os setores ligados ao teatro de grupo se encontrariam em situação de penúria material já que, segundo as denúncias, a produção que se pretende crítica não interessaria aos setores de marketing das grandes empresas sendo, portanto, preterido por esse tipo de financiamento. Ao mesmo tempo, se em algum momento a sustentação financeira com base no consumidor final pôde garantir alguma autonomia à produção, desvinculando o artista de um patrocinador, contemporaneamente a situação é outra, pois:

Segundo as evidências disponíveis, o público para tais atividades encontra-se em declínio [...]. Tal tendência reforça-se mais dada a obsolescência dos espetáculos teatrais e cinematográficos. Diante dessa situação, os grupos de interesse atuantes em cada uma dessas atividades passam cada vez mais a requerer auxílio do Estado, de maneira a compensar os prejuízos que a carência de público e a consequente perda de sustentação no mercado provocam (MICELI, 1984, p.102-103).

Às voltas com tal impasse têm origem as primeiras reuniões do que viria a ser o movimento Arte contra a Barbárie. O ano era 1998 quando alguns diretores teatrais e demais artistas se reuniram para conversar sobre as eleições presidenciais que se aproximavam, a convite de um produtor do Rio de Janeiro ${ }^{7}$. Entre os quais estavam integrantes de seis coletivos identificados ao teatro de grupo da cidade de São Paulo: o TUOV (Teatro Popular União e Olho Vivo), os grupos Tapa,

\footnotetext{
7 As informações contidas neste parágrafo foram extraídas dos materiais do acervo Arte contra a Barbárie, do Arquivo Multimeios.
} 


\section{Politicas culturais e hierarquias simbólicas no campo do teatro paulistano: as lutas pela lei de fomento}

Parlapatões, Patifes \& Paspalhões e Folias d'Arte e as Companhias do Latão e Pia Fraus, todos formados ao longo dos anos 1980-90, à exceção do veterano TUOV , de 1966. Além destes, soma-se a presença de artistas e intelectuais sem o mesmo vínculo, mas de longa e reconhecida trajetória no campo das artes cênicas: Aimar Labaki, Fernando Peixoto, Gianni Ratto e Umberto Magnani. A proposta, naquela ocasião, era construir uma pauta de reivindicações comuns destinadas aos candidatos à presidência da República. Conta-se que o encontro foi infrutífero mas que, por outro lado, teria despertado os produtores paulistas para a necessidade da construção de uma pauta própria. A partir dessa provocação inicial, aquele pequeno grupo continuou se reunindo, semanalmente, com o objetivo inicial de

[...] discutir profundamente nossos problemas e acabamos nos deparando com algumas questões básicas: (1) a dimensão ética do ofício teatral perdida num contexto de mercantilização de todas as relações sociais; (2) a crise de identidade da produção cultural, toda ela confundida com a chamada 'indústria cultural'. Chegamos à conclusão que era preciso criar um fórum que discutisse profunda $\mathrm{e}$ permanentemente política cultural, a partir da discussão de nossa própria realidade e identidade. (ARTE CONTRA A ARBÁRIE, 2001, n.p.).

Com base nessa autodeclaração já é possível identificar, ao menos parcialmente, as disposições incorporadas do grupo, sendo notável o uso do vocabulário crítico comum ao meio acadêmico, como nas denúncias de "mercantilização de todas as relações sociais" ou nas críticas à "indústria cultural", termos que irão pautar o horizonte das lutas propostas pelo Arte contra a Barbárie, conforme veremos. Antes de haver consensos mais específicos, a insatisfação em relação às políticas culturais em vigor e, por sua vez, a dificuldade de manutenção material dessa fração da produção estariam na gênese do agrupamento.

Ainda que, segundo relatos, aquela reunião tenha sido infrutífera, os artistas paulistas continuaram se reunindo semanalmente, reconhecendo afinidades e definindo posições que, a princípio, giravam em torno de críticas à indústria cultural, ao mercado e ao Estado, ou à sua ausência como patrocinador de arte. Para Marco Antonio Rodrigues, que era o diretor artístico do grupo Folias d'Arte, trata-se de um movimento "nascido da constatação que as políticas de cultura no Brasil, que sempre tiveram um caráter elitista, se agudizaram na atuação dos governos contemporâneos [e] A cena investigativa, crítica, que é o que distingue a arte do comércio puro e simples, vai sendo sufocada".(LABAKI, 2000, p.4).

Reivindicando para si o estatuto de artista genuíno em oposição à arte do comércio podemos verificar que, para além de um partido teórico-metodológico do pesquisador, as representações que os próprios agentes constroem de si e do seu trabalho são pautadas pela oposição estruturante entre uma arte pura e uma arte comercial. 
A partir desse consenso mínimo, o grupo continuou se reunindo e depois de seis meses de reuniões privadas, se lançou ao desafio de ir a público através de um manifesto, publicado em 7 de maio de 1999 sob o ambíguo nome de Arte contra a Barbárie. Tal ocasião é tomada enquanto a origem oficial do movimento, já que publiciza pela primeira vez tanto a existência quanto as posições do grupo. Sob o título Artistas promovem debate sobre arte e política, o jornal O Estado de São Paulo dedicou uma matéria em seu caderno de cultura para divulgar o documento. Assinada por Ana Weiss (1999, p.51), ela apresenta o manifesto com a constatação melancólica de que "no Brasil não é possível viver de arte [e que o manifesto representa a] indignação proposta por grupos teatrais e artistas, que levam agora à discussão pública sua avaliação sobre a atual situação da cultura brasileira [e que] o Manifesto é ponto de partida para reformas".

O documento produzido pelo grupo afirma ser “(...) inaceitável a mercantilização imposta à cultura no país” (ARTE CONTRA A BARBÁRIE, 2001, n.p.). De acordo com, Luiz Carlos Moreira, diretor do Engenho Teatral:

O Arte contra a Barbárie, quando surge [...] se caracteriza pelo interesse em algumas questões, a primeira delas é a negação do mercado. [...]. A mercantilização da cultura é a premissa básica que vai fundamentar o movimento no sentido da rejeição dessa mercantilização. Quando o Arte aponta para a questão da Barbárie, no fundo está dizendo que o mercado é a barbárie (COSTA; CARVALHO, 2008, p.64).

Para se contrapor ao mercado, tais artistas buscam problematizar o papel do Estado com relação à cultura, que é afirmada enquanto um elemento "[...] tão fundamental quanto a saúde, o transporte, a educação. É, portanto, prioridade do Estado" (ARTE CONTRA A BARBÁRIE, apud WEISS, 1999, p.51). Inserindo a cultura no rol dos direitos sociais e reivindicando o protagonismo estatal no financiamento às artes, o grupo procurou se opor às chamadas políticas neoliberais, que estavam então no centro da crítica social à esquerda. No bojo dessa discussão ganha força o combate aos chamados eventos mercantis, categoria que ganhará centralidade nos discursos e proposições do movimento. Aspecto que adquire pleno sentido quando miramos o horizonte histórico e político que então se vivia. Enquanto que na esfera federal Francisco Weffort (BRASIL, 1995) afirmava que a "cultura é um bom negócio" e promovia uma política de eventos", localmente, sob a criticada administração municipal encabeçada por Celso Pitta (1997-2001), era

\footnotetext{
8 Referência à cartilha do mesmo nome, divulgada pelo ex-ministro. Nela, fazia-se um convite para a iniciativa privada investir em cultura via leis de incentivo, explicando abertamente sobre os ganhos de marketing decorrentes de tal prática, através da visibilidade de mídia etc. (BRASIL, 1995).

9 Caracterizada pela ação fragmentária e pela descontinuidade. Para alguns, ela seria o exato oposto da política cultural, justamente por não ter consequências duráveis.
} 


\section{Politicas culturais e hierarquias simbólicas no campo do teatro paulistano: as lutas pela lei de fomento}

frequente que em debates, palestras e reportagens o titular da Secretaria de Cultura, Rodolfo Konder, procurasse provar o desempenho de sua gestão utilizando-se de uma estatística mensal de eventos realizados sem revelar, entretanto, como tais números eram recolhidos e o que de fato significavam (DURAND, 2001).

Indo de encontro a tal modelo de gestão e de política cultural, emerge o combate aos eventos mercantis e, em contrapartida, a defesa de uma produção continuada. Detratando a prática artística orientada pela produção ocasional, o Arte contra a Barbárie (2008a, n.p.) distingue aquela onde há o "privilégio do processo sobre o produto", expressão recorrente em seus discursos e que irá se impor como critério de legitimidade para julgar o teatro detentor de valor simbólico. Na avaliação de Sergio de Carvalho (2003), docente, pesquisador e diretor da Companhia do Latão, isso significou um deslocamento no qual o conceito de trabalho teatral tornouse mais importante do que a obra de arte. Importante destacar que o manifesto não apresenta um combate direto às leis de incentivo, adotando o tom da crítica mais implícita ao afirmar, por exemplo, que "é imprescindível uma política estável para a arte teatral [e que ela] implica em mecanismos estáveis e permanentes de fomento à pesquisa e à experimentação teatral" (ARTE CONTRAA BARBÁRIE apud WEISS, 1999, p.51). Com efeito, o exame dos materiais documentais indicam que não havia consenso no movimento sobre as leis de incentivo, ou que o único consenso era sobre o seu caráter injusto, dado os critérios privados com que os recursos públicos eram empregados. No mais, o Arte contra a Barbárie congregava desde aqueles que defendiam reformas na lei Rouanet, até o extremo oposto, representado pelos que acreditavam que o melhor seria a extinção completa do mecanismo.

Três dias após sua publicação, o documento foi apresentado ao público no Teatro da Aliança Francesa que, na ocasião, sediava o Grupo Tapa. Conta-se que sua repercussão foi muito maior que a esperada em meio à categoria, atraindo centenas de pessoas e sendo responsável por ampliar o contingente de interessados em participar daquelas reuniões semanais (COSTA; CARVALHO, 2008). Sobre isso, para além da disposição encontrada junto à categoria, não se pode deixar de notar que tanto o manifesto quanto o convite ao debate foram divulgados por um dos principais cadernos de cultura da cidade, para o qual ao menos dois dos agentes em questão já haviam colaborado como críticos teatrais - fato que, provavelmente, viabilizou a publicação.

Com intervalo de seis meses, o movimento lançou um segundo manifesto, que surgiu como uma espécie de balanço do primeiro, mas produzido agora por um quadro ampliado de participantes, dentre os quais estão os antigos Teatro Oficina e o Engenho Teatral e as jovens Companhia do Feijão e Companhia São Jorge de Variedades, para citar tão somente os que nos parecem mais representativos, seja pelos documentos apontarem uma participação mais durável, seja porque incidiram de maneira mais expressiva em seu desenvolvimento. Tais grupos compuseram a 
"segunda dentição" do Arte contra a Barbárie - como eram referidos pela categoria nativa -,atraída para o movimento não só através da identificação com as ideias contidas no primeiro manifesto mas, sobretudo, em decorrência dos debates e palestras promovidos a partir daquela publicação e que, no mais das vezes, contavam com a presença de intelectuais muito prestigiados como o geógrafo Milton Santos e o filósofo Paulo Arantes. Segundo Eduardo Tolentino de Araújo, diretor do Grupo Tapa, a partir da publicação do primeiro manifesto os grupos

[...] foram procurando o pessoal da USP (Universidade de São Paulo), da imprensa, e a coisa foi crescendo... nas reuniões começamos a ver os segmentos com os quais discutiríamos: imprensa, jornalistas [sendo que] algumas pessoas do meio acadêmico e intelectual já eram ligadas a alguns dos projetos ou grupos (ARAÚJO, 2016).

As palavras de Tolentino, somadas ao acesso facilitado a determinados espaços e publicações, dão a ver o grau de proximidade que tais agentes nutriam em relação à intelectualidade e demais instâncias de legitimação cultural revelando, por sua vez, senão a posse de capital econômico, a de capital social e cultural. Dispondo desses trunfos, a estrutura de organização do movimento foi definida desde então a partir de dois eixos: reuniões públicas semanais com a presença de convidados oriundos do meio cultural e/ou acadêmico para discutir temas estratégicos; e reuniões internas para encaminhar o que fosse discutido ali. Através do exame de materiais de arquivo verificamos que não se discutiam princípios estéticos ou artísticos, stricto sensu. Mas, o que permitia estabelecer alianças entre os grupos era o combate a um inimigo comum: o mercado, representado pelo teatro comercial e pelos eventos mercantis. Sendo assim, foi de maneira contrastiva, através dessas recusas e da consequente identificação construída a partir da adoção de um procedimento de trabalho, o processo colaborativo, que o movimento adquiriu sua identidade propriamente artística.

Nesse sentido, o segundo manifesto reafirma o compromisso com uma política pública onde a "ação eventual seja substituída pela ação sistemática e contínua que possibilita a qualidade e a excelência" (ARTE CONTRA A BARBÁRIE, 2008a, n.p.) definindo, nesses termos, a maneira correta de fazer a representação. A partir dessa segunda publicação, seguida de uma nova série de debates e palestras com intelectuais renomados, o movimento tornou-se amplamente conhecido como Arte contra a Barbárie. Procedendo a um balanço de sua atuação até aquele momento, viu-se que "amplos setores, das mais variadas linguagens artísticas de diferentes estados da União se organizaram e se manifestaram. Encontros, debates e seminários foram organizados espontaneamente mostrando a urgência e importância da questão cultural" (ARTE CONTRA A BARBÁRIE, s/d.-a, n.p.), dando a ver 


\section{Politicas culturais e hierarquias simbólicas no campo do teatro paulistano: as lutas pela lei de fomento}

a repercussão que o movimento conquistou no interior dos campos da produção cultural. Efetivamente, a partir do Arte contra a Barbárie tiveram origem o Fórum de Cinema, tentativa de organizar esse setor da produção, e, mais tarde, a criação e aprovação da Lei de Fomento à Dança (SÃO PAULO, 2005) em tudo similar à de teatro.

Em seguida, como resultado do acúmulo de um ano de discussões sistemáticas, foi publicado um terceiro manifesto Arte contra a Barbárie que reitera as críticas, mas que avança propositivamente ao anunciar:

A criação de Programas Permanentes para as Artes Cênicas no âmbito municipal, estadual e federal, com recursos orçamentários e geridos com critérios públicos e participativos [como também] A criação do Espaço da Cena, encontros públicos quinzenais para o debate permanente de política cultural e dos fundamentos do nosso ofício, o teatro. (ARTE CONTRA A BARBÁRIE, 2008b, n.p.).

Tal momento revela uma inflexão na trajetória do movimento, na qual se desdobram duas estratégias complementares. A primeira consistiu na formulação de uma política cultural, o Programa de Fomento, que a partir de então vai nortear as ações do Arte contra a Barbárie. Segundo relatos, o ingresso de Luiz Carlos Moreira ao grupo foi fundamental no sentido de conformar tal estratégia. Moreira ${ }^{10}$ foi um dos fundadores da Cooperativa Paulista de Teatro no final da década de 1970 mesma entidade que representa a maioria absoluta dos grupos da atualidade - e será reconhecido como referência política do movimento e o responsável por O Arte começa discutindo essa hegemonia [referindo-se à arte comercial e a indústria cultural] e, percebendo que eles [os grupos de teatro] estavam sempre a reboque de programas governamentais mais ou menos simpáticos à questão cultural. Daí que surge a ideia de trabalhar sobre o poder legislativo. encabeçar a proposta que, nos seus dizeres, representou "uma resposta que a gente tinha que dar naquele momento, a resposta que a gente escolheu - então, tratava-se de uma escolha política entre várias". Marco Antonio Rodrigues (2016) entende esse estágio do movimento e a definição dessa estratégia nos seguintes termos: "O Arte começa discutindo essa hegemonia [referindo-se à arte comercial e a indústria cultural] e, percebendo que eles [os grupos de teatro] estavam sempre a reboque de programas governamentais mais ou menos simpáticos à questão cultural. Daí que surge a ideia de trabalhar sobre o poder legislativo".

Forma-se, então, um Grupo de Trabalho, referido em documentos como GT do Fomento, com o objetivo de elaborar um programa nos termos do manifesto para ser posteriormente submetido ao debate e aprovação nos fóruns do movimento.

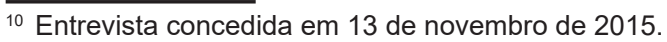


Partindo da premissa de que "É dever do Estado manter determinadas manifestações teatrais" o Programa parte do entendimento de que:

[...] são esses coletivos e seu trabalho contínuo que podem construir e manter um teatro vital para a cidade. Caso contrário, não passaria de um apoio assistencial, parcial, corporativo, a um segmento da produção teatral. Logo, o fomento é um programa que pretende consolidar um teatro fundamental para a cidade, através de recursos permanentes do município, e diz que esse é o papel dos núcleos artísticos com propostas de trabalho continuado [...]. Pode-se dizer que o teatro fundamental para a cidade implica mexer nas relações de trabalho e nas técnicas de criação [e que] trabalho continuado implica [...] objetivos diferentes daqueles que norteiam um profissional dentro da produção da novela, do musical da Broadway, da comédia de gabinete, por exemplo. [...] O que se espera é que elas possibilitem e exijam a criação de novas poéticas, mais adequadas a essas formas de trabalho e criação. (ARTE CONTRA A BARBÁRIE. Fomento. Programa Público. Continuidade, s/d-b, n.p.).

Paralelamente à elaboração do Programa de Fomento ao Teatro, o movimento passou a produzir uma nova série de debates e palestras denominados de Espaço da Cena que, além de agregar capital simbólico e dar maior visibilidade ao grupo, também o nutria da convicção de que produziam o teatro fundamental para a cidade. Chegamos, assim, à outra face da estratégia. Tendo já avaliado a repercussão atingida através da promoção de debates públicos contando com expoentes renomados da intelectualidade, a criação do Espaço da Cena iria configurar-se na principal estratégia de legitimação do Arte contra a Barbárie, complementar à elaboração de uma política cultural. Pois trata-se da construção de um espaço público de discussão e, portanto, de divulgação de ideias que, ao detratar o teatro comercial e os valores mercantis, qualificaria como legítima a produção dos grupos. Em seguida ao lançamento do terceiro manifesto tiveram início os encontros Espaço da Cena que, ainda nos anos 2000, promoveram um debate com as entidades teatrais da cidade $^{11}$ e outro com os candidatos à prefeitura municipa $1^{12}$, numa possível tentativa de buscar apoio ao Programa em elaboração. Para o ano seguinte, definiu-se que o tema que iria unir todos os debates seria Produção teatral - modo de produção, em conformidade com o ponto nevrálgico da nova legitimidade artística. Dentre os convidados que animaram esse novo ciclo de debates encontramos nomes como

\footnotetext{
11 No caso a Cooperativa Paulista de Teatro, o SATED (Sindicato dos artistas e técnicos em espetáculos de diversão de São Paulo) e a Apetesp (Associação dos Produtores de Espetáculos teatrais do Estado de São Paulo).

12 Foram convidados os principais candidatos ao pleito, mas verificou-se apenas presença do então candidato Geraldo Alckmin, do Partido da Social Democracia Brasileira (PSDB) e de seu coordenador de campanha, Walter Feldman.
} 


\section{Politicas culturais e hierarquias simbólicas no campo do teatro paulistano: as lutas pela lei de fomento}

Otília Arantes, Maria Rita Kehl, Iná Camargo Costa - tendo esta se tornado uma espécie de militante do movimento.

Após alguns meses de estudos e de estruturação da proposta, será apresentado o Programa de Fomento ao Teatro para a Cidade de São Paulo, que tem por objetivo "a criação de projetos de trabalhos continuados de pesquisa e produção teatral, visando o desenvolvimento do teatro e o melhor acesso da população ao mesmo" (SÃO PAULO, 2002. Art. $1^{\circ}$ ), por intermédio de grupos profissionais a serem financiados diretamente por este programa. E, se o Programa não impõe um gênero ou temática para os projetos que desejariam acessar tais recursos (como foi o caso de políticas elaboradas pelo SNT durante a Era Vargas ou a ditadura militar), ele impõe um padrão de trabalho artístico - os coletivos teatrais com trabalho continuado como único legítimo de receber recursos. Além daquele objetivo, o Programa conformará os demais princípios da nova legitimidade artística, explicitados fundamentalmente no Art. 14, que define os critérios de apreciação a serem adotados pela comissão julgadora, que devem compreender, além daquele objetivo,

II - Planos de ação continuada que não se restringem a um evento ou a uma obra. $[\ldots]$

V - A compatibilidade e qualidade na relação entre prazos, recursos e pessoas envolvidas no plano de trabalho.

VI - A contrapartida social ou benefício à população conforme plano de trabalho. VII - O compromisso de temporadas a preços populares quando o projeto envolver a produção de espetáculo.

VIII - A dificuldade de sustentação econômica do projeto no mercado. (SÃO PAULO 2002, n.p.)

Assim se consubstanciaram as discussões que vinham sendo empreendidas desde 1998 e, depois de aprovado pelo movimento, o Programa foi lançado ao conhecimento público em uma reunião Espaço da Cena. Ao mesmo tempo em que divulgava o Programa de Fomento e buscava adesão de outros grupos através de assinaturas, o movimento ampliava seu escopo de atuação e ganhava visibilidade através desse fórum de discussão, atraindo para si a autoridade de célebres expoentes da intelectualidade brasileira que, numa espécie de contágio simbólico (BOURDIEU, 2014), transferiam parte de seu prestígio ao escopo do Arte contra a Barbárie, conferindo-lhe legitimidade cultural. O que pode ser verificado através da cobertura dos jornais de grande circulação da cidade ${ }^{13}$ que, desde então, dedicaram ainda mais espaço em suas mídias para noticiar os passos do movimento, divulgando, inclusive, parte de suas atividades públicas.

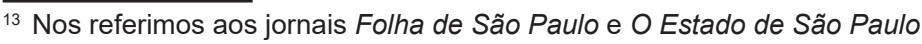


Dotados de maior reconhecimento público e valor simbólico, em dezembro de 2000 o Arte contra a Barbárie organizou um ato público para protocolar o Programa de Fomento na Câmara Municipal de São Paulo. Fato noticiado em matéria veiculada pela Folha de São Paulo, onde lê-se que:

Muitos torceram o nariz para o movimento quando ele surgiu, em maio de 1999 [mas que ele teria] superado divergências estéticas e ideológicas, vinculando-se a outras áreas, além de atrair intelectuais [ e que, naquele mesmo dia da publicação] iria protocolar, na Câmara Municipal, o Programa de Fomento ao teatro para a cidade de São Paulo, [explicando que nele] a chave é insistir em projetos de pesquisas dramatúrgicas ou cênicas, não somente em produção final (montagens) como prega as leis de incentivo. (SANTOS, 2000, p.E3).

Perfazendo a trajetória do movimento até aqui temos que a atuação dos grupos em torno ao Arte contra a Barbárie foi responsável por aglutinar essa fração do campo que, através dele, logrou atingir certo grau de legitimidade e visibilidade pública, difundindo convicções artísticas, interesses, formas de pensamento, críticas, vontades e, mesmo, um padrão de trabalho legítimo, condensado pelo Programa protocolado como Projeto de Lei na Câmara Municipal de São Paulo.

Mas, a despeito do reconhecimento conquistado no campo cultural, ao eleger a via legislativa como estratégia restava ao movimento de artistas estabelecer alianças com o campo do poder. Olhando para o horizonte político que então se vivia, tal escolha torna-se mais inteligível, já que localmente o clima político era de otimismo, marcado pela possibilidade real de retomada da administração municipal pelo Partido dos Trabalhadores (PT). De acordo com pesquisas, a candidata petista Marta Suplicy contava, às vésperas da eleição, com $31 \%$ das intenções de voto, à frente por 14 pontos percentuais do $2^{\circ}$ colocado, o candidato Paulo Maluf do Partido Progressista Brasileiro (PPB), no $1^{\circ}$ turno do pleito (DATAFOLHA, 2000a). Vantagem que aumentava na disputa em $2^{\circ}$ turno, onde a petista aparecia com $58 \%$ das intenções de voto, 30 pontos percentuais à frente de seu oponente (DATAFOLHA, 2000b). Importante ressaltar que se tratava de um momento no qual o PT angariava grandes expectativas entre os militantes da cultura. Isto porque, na experiência anterior do partido no comando do município, quando elegeu a nordestina Luiza Erundina (1989-1993) em decorrência de lutas sociais e processos de mobilização popular, a então prefeita convidou a filósofa Marilena Chauí para assumir a Secretaria de Cultura, e esta levou a cabo uma gestão pautada pela recusa do modelo liberal instituindo, localmente, o conceito de cidadania cultural (CERQUEIRA, 2018).

Não por acaso, a primeira aliança será estabelecida com o então vereador Vicente Cândido (PT) ${ }^{14}$ que acolheu o Programa de Fomento integralmente,

\footnotetext{
${ }_{14}$ Atualmente deputado federal pelo mesmo partido.
} 


\section{Políticas culturais e hierarquias simbólicas no campo do teatro paulistano: as lutas pela lei de fomento}

tornando-se uma espécie de procurador parlamentar do Arte contra a Barbárie (COSTA; CARVALHO, 2008). Segundo Aimar Labaki ${ }^{15}$, tal parceria foi possível, primeiramente, a partir de laços de amizade, já que o Vicente Cândido era amigo pessoal de Marco Antônio Rodrigues. Segundo a narrativa deste último: "O Vicente era amigo da gente há muito tempo [e] quando a comissão do fomento estava estruturando a lei, ele já estava, o Vicente já era um militante da cultura. Então, naturalmente era ele, que sempre foi um cara que apoiou isso". (RODRIGUES, 2016).

Além de Vicente Cândido, o cenário que se formou contou, ainda, com José Eduardo Cardozo ${ }^{16}$ presidindo a Câmara Municipal e com Celso Frateschi ${ }^{17}$ no comando da Secretaria Municipal de Cultura da gestão Marta Suplicy que, confirmando os prognósticos, foi a prefeita eleita e empossada em janeiro de 2001. Enquanto acompanhava a tramitação do Projeto de Lei na Câmara Municipal, o Arte contra a Barbárie seguia reunido em seus fóruns e organizava uma edição dos debates ocorridos no Espaço da Cena, além de planejar seu novo formato para 2002. Projetos que não se concretizaram, provavelmente, por causa das demandas advindas da aprovação do Programa de Fomento que foi convertido, sem nenhuma alteração da redação original, no Projeto de Lei no 416/00 do vereador Vicente Cândido, aprovado pela Câmara em dezembro de 2001 e promulgado pela prefeita Marta Suplicy 08 de janeiro do ano seguinte coroando, assim, as lutas dos grupos teatrais da cidade por uma políticas públicas de cultura.

Assim foi instituída a primeira lei do país a apoiar coletivos de teatro e a valorizar processos de pesquisa, não resultados acabados (CARVALHO, 2009). Feito que será reconhecido com uma homenagem do Prêmio Shell, de notória excelência no campo artístico, e noticiado pelos principais jornais da cidade. O Estado de São Paulo traduziu esta consagração enquanto "homenagem ao fecundo movimento da classe teatral envolvendo mais de 300 pessoas" (BRASIL, 2002, p.40). Já a matéria publicada na Folha de São Paulo julgou que "A homenagem é graças à contribuição do movimento ao desenvolvimento crítico do teatro" (SANTOS, 2002, p.E3).

\footnotetext{
${ }^{15}$ Em entrevista concedida via correio eletrônico, em 09 de maio de 2016.

${ }^{16}$ Ex-ministro dos dois governos Dilma Rousseff (2010-2016). No âmbito da Câmara Municipal, Cardozo notabilizou-se por ter sido o principal expoente das denúncias de corrupção contra vereadores da bancada do então prefeito Celso Pitta (PPB).

${ }_{17}$ Celso Frateschi é ator, diretor e autor de teatro. Possui longa e reconhecida trajetória no campo das artes cênicas. Que, paralelamente às suas atividades artísticas, é marcada pela ocupação de postos ligados às políticas culturais: foi Secretário de Cultura de Santo André na gestão Celso Daniel (PT), quando impulsionou a criação da Escola Livre de Teatro, referencial na divulgação do "processo colaborativo. Foi também diretor do Departamento de Teatro de São Paulo, onde impulsionou os projetos Formação de Público e Vocacional, ambos referenciais no campo das políticas para o setor teatral e de interesse ao desenvolvimento do teatro de grupo. Desde 1980, Frateschi é também professor da EAD/USP (Escola de Arte Dramática/USP) e é proprietário do Teatro Ágora, localizado na região central de São Paulo.
} 
Ao examinar esse percurso, ainda que se reconheça o indiscutível mérito cultural tanto do Programa de Fomento quanto do movimento que o impulsionou, esperamos ter demonstrado que sua conversão em Lei Municipal só se tornou possível graças a uma configuração específica do campo naquele momento e da mobilização de diversas espécies de capitais.

\section{Impasses e contradições do fomento público}

De lá para cá, a cidade de São Paulo se tornou uma espécie de laboratório compulsório de pesquisas e experimentações cênicas, viabilizadas pela Lei de Fomento. Fato que, como não poderia deixar de ser, trouxe consigo novos impasses e contradições.

De maneira imediata, a primeira consequência da aprovação da Lei de Fomento foi a desmobilização do movimento que lhe deu origem. Pouco a pouco, o Arte contra a Barbárie, movimento de reconhecida importância na cena local por pautar os debates sobre política cultural e, ao mesmo tempo, denunciar o caráter injusto das leis de incentivo fiscal, foi tendo seus fóruns esvaziados. Enquanto tal, pode-se dizer que ele continuou existindo, mesmo que de maneira exígua, por via de um jornal intitulado $O$ Sarrafo. De circulação nacional e divulgado por meio impresso e digital, ele chegou a atingir certa repercussão, ainda que diminuta quando comparada à efervescência das discussões semanais dos anos anteriores. De qualquer forma, o jornal teve vida curta, atingindo nove números, com a última edição datando de abril de 2006, data que pode ser tomada como de dissolução definitiva do movimento.

Imediatamente após a conquista da Lei de Fomento, também foi possível observar o crescimento do número de coletivos teatrais produzindo a partir de processos colaborativos e circulando em espaços fora do circuito convencional. Ganho, entretanto, difícil de sustentar, pois a Lei de Fomento se mostrou insuficiente para suprir as demandas desses grupos, fazendo crescer as disputas internas pelo fomento e suscitando, inclusive, acusações entre os pares. Diversas foram as denúncias de que haveria grupos privilegiados, por serem contemplados em seguidas edições enquanto outros não conseguiam acessar os recursos. Nesse sentido, a Lei de Fomento teria se transformado na Lei do Tormento convertendo-se, nos dizeres de Paulo Arantes, "numa conquista histórica cada vez mais difícil de carregar. [...] Curiosa autonomia essa, cujo gozo provoca dependência" (ARANTES, 2012, p.200-201).

Com efeito, se a recusa do mercado e a reivindicação por maior autonomia para a criação teatral constituíram o principal móvel das lutas em torno ao Arte contra a Barbárie, tal reivindicação vai esbarrar com novas formas de dependência. 


\section{Politicas culturais e hierarquias simbólicas no campo do teatro paulistano: as lutas pela lei de fomento}

Seja em relação ao Estado, seja em relação ao próprio mercado. Já que, por um lado, frente ao crescimento do número efetivos e das disputas internas, novamente a saída foi requerer auxílio do Estado - nos referimos à criação do Prêmio Zé Renato (SÃO PAULO, 2014), um nova modalidade de apoio ao desenvolvimento teatral, vinculado à Secretaria Municipal de Cultura, criada para apoiar produção e desenvolvimento da atividade teatral desenvolvida por núcleos artísticos e pequenos e médios produtores independentes com vistas à produção de espetáculo e realização de temporada ou circulação na cidade de São Paulo. De certa forma, o prêmio veio como resposta às críticas e acusações de favorecimento observadas na Lei de Fomento, já que nele a prioridade aqui são os grupos mais jovens. O prêmio foi instituído em 2014, durante a gestão de Fernando Haddad (PT). Mas, por outro lado, o financiamento estatal não pode ser visto como um meio que permite autonomia frente aos circuitos de comercialização da arte, já que ele próprio faz parte do mercado, embora não seja idêntico a ele. Nesse sentido, a despeito do critério que preconiza a continuidade do trabalho artístico, a Lei de Fomento não oferece garantias ao desenvolvimento do trabalho de determinado grupo depois de terminado o subsídio, que é temporário. Mesmo na avaliação posterior de um dos quadros do Arte contra a Barbárie, isso teria levado os grupos a um movimento de profissionalização precária, pois

[...] a ampliação da base produtiva dos grupos constituiu pouco a pouco um movimento de profissionalização que criou novas dependências mercantis. Em grupos antes semiamadores e inventivos, cresceram as contas a pagar, a necessidade de acumulação e reinvestimento de capital, cresceram as contradições entre um salário salvador e a precária realidade do semiprofissionalismo dos grupos (CARVALHO, 2009, p.162-163).

Questão emblemática disso é a locação de espaços para servir como sede de trabalho de determinado grupo quando contemplado pela Lei de Fomento. Se por um lado essas sedes são, em grande medida, responsáveis por descentralizar a produção e criar novos circuitos de produção e circulação teatral, por outro sua manutenção tem gerado inúmeras controvérsias. Primeiro porque, como explica José Fernando Azevedo (2012, p.218-219), elas "misturam uma prática contratual privada (aluguéis, por exemplo) a uma instância mantenedora pública (o aporte do Fomento) legitimada por um uso público do espaço". Além disso, já que os contratos de locação têm prazo superior a uma edição de fomento, terminado o subsídio os artistas precisarão arcar com sua manutenção através de outros meios, ficando mais suscetíveis ao mercado e assumindo um compromisso empresarial, portanto. Têm sido frequentes os impasses vividos pelos grupos para manter suas sedes, envolvendo embates entre grupos teatrais e representantes do mercado imobiliário. Até mesmo grupos consolidados na cena contemporânea, dos quais a já citada Companhia São 
Jorge de Variedades, entre tantos outros, tiveram seus trabalhos comprometidos depois de perder seu espaço próprio. A questão é polêmica e tem gerado inúmeras discussões que dão a ver, também, a fragilidade da Lei de Fomento enquanto ela não estiver amparada por um conjunto mais amplo de políticas para o setor.

Por fim, partindo do pressuposto de que todo edital cria uma demanda, é questionável a medida em que aquilo que é reivindicado como um meio de garantir maior autonomia artística não teria se tornado um fim em si mesmo. Nesse sentido, recorrendo novamente às considerações de Sergio de Carvalho (2009, p.163), "muitos experimentos livres [teriam] se tornado fórmulas de acerto, e alguns estilos [...] se converteram em fórmulas imitadas na medida em que passaram a despertar interesse no mundinho dos festivais de teatro". Se é assim, outro efeito da Lei de Fomento seria plasmar os experimentos cênicos ao vincular o apoio estatal à defesa da superioridade estética de um teatro de pesquisa, critério da nova legitimidade artística que enquanto tal, atingiu não apenas a produção dos coletivos interessados mas, também, as escolas de formação e as instâncias de consagração - conforme atestam, por exemplo, as modificações observadas em um dos cursos superiores de Artes Cênicas mais prestigiados do campo, ${ }^{18}$ que passou recentemente por uma reestruturação curricular com objetivo de se adaptar aos procedimentos do processo colaborativo. Nesse sentido, é possível afirmar que as lutas que culminaram com a Lei de Fomento impactaram todo o campo da produção. Entretanto, cumpre destacar que, apesar de sua grande repercussão não dispomos, ainda, de uma visão analítica do conjunto dos projetos subsidiados pela Lei de Fomento, capaz de avaliar as relações entre o financiamento público ao teatro e suas consequências em termos de espetacularidade, recepção e formação.

\section{Cultural POLICIES AND SYMBOLIC hIERARChIES in the field of São PaUlo theatre: the STRUGGLES FOR THE LAW FOR PROMOTION}

ABSTRACT: This article discusses the trajectory of the movement 'Art against Barbarism' from its genesis to its most notorious achievement: Law for Promotion of Theater for the city of São Paulo, which constitutes an innovation in the panorama of public policies in the Brazilian context. By illuminating this course, we seek to highlight the strategies of cultural legitimation used by the movement, as well as the determinants which contributed to make such an achievement possible.

KEYWORDS: Theater. Cultural Policies. Symbolic Hierarchies. Cultural Legitimacy.

${ }^{18}$ Nos referimos ao curso de graduação oferecido pela Escola de Comunicações e Artes da USP. 
Politicas culturais e hierarquias simbólicas no campo do teatro paulistano: as lutas pela lei de fomento

\section{Políticas CULTURales Y JeRARQUías SIMBOLICAS EN EL CAMPO DEL TEATRO PAULISTANO: LAS LUCHAS POR LA LEY DE FOMENTO}

RESUMEN: En este artículo se discute la trayectoria del movimiento 'Arte contra la barbarie', desde su génesis hasta su logro más notorio: la Ley de Fomento al Teatro, para la ciudad de São Paulo, que constituye una innovación en el panorama de las políticas públicas en el contexto brasileño. Al iluminar este camino, buscamos resaltar las estrategias de legitimación cultural que el movimiento utilizó, así como la evidencia de los factores que contribuyeron a hacer posible tal conquista.

PALABRAS CLAVE: Teatro. Politicas culturales. Jerarquías simbólicas. Legitimidad cultural.

\section{REFERÊNCIAS}

ARANTES, Paulo Eduardo. A lei do tormento. In: DESGRANGES, FLAVIO \& LEPIQUE, Maysa (orgs.). Teatro e vida pública: o fomento e os coletivos teatrais de São Paulo. São Paulo: Hucitec, 2012.

ARAÚJO, Eduardo Tolentino de. Entrevista por telefone concedida para a pesquisa em 22 de junho de 2016.

ARTE CONTRA A BARBÁRIE. Segundo Manifesto. In: COSTA, Iná Camargo \& CARVALHO, Dorberto. A luta dos grupos teatrais de São Paulo por políticas públicas para a cultura: os cinco primeiros anos da lei de fomento ao teatro. São Paulo: Cooperativa Paulista de Teatro, p.23-26, 2008a [1999].

. Terceiro Manifesto. In: COSTA, Iná Camargo \& CARVALHO, Dorberto. A luta dos grupos teatrais de São Paulo por políticas públicas para a cultura: os cinco primeiros anos da lei de fomento ao teatro. São Paulo: Cooperativa Paulista de Teatro, p.29-30, 2008b [2000].

. Arte contra a Barbárie: histórico e propostas. Documento do acervo Arte contra a Barbárie, Arquivo Multimeios, Centro Cultural São Paulo. 2001.

. Minuta: balanço. Documento do acervo Arte contra a Barbárie, Arquivo Multimeios, Centro Cultural São Paulo. s/d.a.

. Fomento. Programa Público. Continuidade. Documento do acervo Arte contra a Barbárie, Arquivo Multimeios, Centro Cultural São Paulo. s/d.b 
ARRUDA, Maria Arminda do Nascimento. Metrópole e Cultura: São Paulo no meio do século XX. 2. ed. São Paulo: Editora da Universidade de São Paulo, 2015.

AZEVEDO, Luiz Fernando Ramos. Fomento: para além das ideologias, estratégias para inventar novos teatros. In: DESGRANGES, FLAVIO; LEPIQUE, Maysa (orgs.). Teatro e vida pública: o fomento e os coletivos teatrais de São Paulo. São Paulo: Hucitec, 2012.

BOURDIEU, Pierre. A produção da crença: contribuição para uma economia dos bens simbólicos. Porto Alegre, RS: Zouk: 2014.

. As regras da arte: gênese e estrutura do campo literário. Lisboa: Editorial Presença, 1996.

BRASIL, Ubiratan. "Pólvora e poesia consagra-se no prêmio Shell”. O Estado de São Paulo. Caderno 2, p. 40, edição de quarta-feira, 13 de março de 2002.

BRASIL. MINISTÉRIO DA CULTURA. Cultura é um bom negócio. Brasília-DF, 1995.

BRASIL. LEI No 8.813, DE 23 DE DEZEMRO DE 1991. Restabelece princípios da Lei ${ }^{\circ}$ 7.505, de 2 de julho de 1986, institui o Programa Nacional de Apoio à Cultura (Pronac) e dá outras providências. Disponível em: <http://www.planalto.gov.br/ccivil_03/Leis/L8313cons. htm. Acessado em: 3 jul. 2018.

BRASIL. LEI N 7.505, DE 2 DE JULHO DE 1986. Dispõe sobre benefícios fiscais na área do imposto de renda concedidos a operações de caráter cultural ou artístico. Disponível em: <http://www.planalto.gov.br/ccivil_03/LEIS/L7505.htm?TSPD_101_R0 $=0672$ dea $9 \mathrm{a} 85183 \mathrm{a} 91724 \mathrm{~b} 570 \mathrm{c} 24 \mathrm{bbef} 2 \mathrm{dA} 00000000000000000 \mathrm{c} 36114 \mathrm{bdffff} 0000000000$ $0000000000000000005 \mathrm{~b} 3 \mathrm{e} 6 \mathrm{c} 020075 \mathrm{~d} 3244508282 \mathrm{a} 9212 \mathrm{ab} 20009 \mathrm{f} 5 \mathrm{fd} 61 \mathrm{e} 7 \mathrm{~b} 8 \mathrm{bd} 6271 \mathrm{e} 651$ f49d8c2d68f1091f85f72d84012f9fc4be1d30c2fd9086ef0c7f60a280034b5cf917adfee7ec b6a3242dbb659456a7738d632ff340d2e878fa321 ebbd7a13dca00c196554ba>. Acessado em: 5 jul. 2018.

CALABRE, Lia. Políticas culturais no Brasil: dos anos 1930 ao século XXI. Rio de Janeiro: FGV, 2009.

CARVALHO, Sergio de (org.) Introdução ao teatro dialético: experimentos da Companhia do Latão. São Paulo: Expressão Popular, 2009.

CARVALHO, Sergio de. O teatro de grupo e a mercantilização da cultura. Palestra proferida no Hemispheric Institute. São Paulo, 17 de janeiro de 2003.

CERQUEIRA, Amanda Patrycia Coutinho de. Política cultural e trabalho nas artes: o percurso e o lugar do Estado no campo da cultura. Revista Estudos Avançados. São Paulo: n. 32, vol. 92. p.19-139, junho de 2018.

COSTA, Iná Camargo. A Hora do Teatro Épico no Brasil. Rio de Janeiro: Paz e Terra, 1996 


\section{Políticas culturais e hierarquias simbólicas no campo do teatro paulistano: as lutas pela lei de fomento}

COSTA, Iná Camargo \& CARVALHO, Dorberto. A luta dos grupos teatrais de São Paulo por políticas públicas: os cinco primeiros anos da Lei de Fomento. São Paulo: Cooperativa Paulista de Teatro, 2008.

DATAFOLHA. Pesquisa Intenção de voto prefeito São Paulo - 10 turno (em \%), realizada em 1 de outubro de 2000a. Disponível em < http://media.folha.uol.com.br/datafolha/2013/05/02/ intvoto_pref_sp_01102000.pdf>.Acessado em: 10 jul. 2018.

. Pesquisa Intenção de voto prefeito São Paulo - 2o turno (em \%), realizada em 29 de outubro de 2000b. Disponível em: <http://datafolha.folha.uol.com.br/ eleicoes/2000/10/1196287-intencao-de-voto-prefeito-sao-paulo---2o-turno-em-.shtml>. Acessado em: 10 jul. 2018.

DESGRANGES, Flavio. A inversão da olhadela: alterações no ato do espectador teatral. São Paulo: Hucitec, 2012.

DURAND, José Carlos. Cultura como objeto de política pública. São Paulo em perspectiva. São Paulo, vol.15, n 2, p.66-72, abril/junho de 2001. Disponível em: <http:/www.scielo.br/ pdf/spp/v15n2/8579.pdf>. Acessado em: 15 jul. 2016.

LABAKI, Aimar. Entrevista: o diretor de teatro Marco Antonio Rodrigues do grupo Folias d'Arte fala à Revista Camarim sobre o movimento que tem agitado a classe teatral. Revista Camarim, n.14, vol.3. p.4-5, 2000.

MICELI, Sergio. (org.). Estado e Cultura no Brasil. São Paulo: Difel, 1984. . Intelectuais e classe dirigente no Brasil. São Paulo: Difel, 1979.

RODRIGUES, Marco Antônio. Entrevista concedida para a pesquisa em 6 de fevereiro de 2016.

ROMEO, Simone do Prado. O movimento arte contra a barbárie: gênese, estratégias e legitimação e princípios de hierarquização das práticas teatrais em São Paulo (1998-2002). Dissertação. Pós-graduação em Ciências Sociais. UNIVERSIDADE FEDERAL DE SÃO PAULO, 2016.

RUBIM, Antonio Albino Canelas; BAYARDO, Rubens. (Orgs.). Políticas culturais na ibero-américa. Salvador: EDUFBA, 2008.

SANTOS, Valmir. Movimento faz ato na Câmara e inspira outras capitais do país. Folha de São Paulo, Ilustrada, p.E3, edição de quarta-feira, 6 de dezembro de 2000.

. Shell premia Leopoldo Pacheco e Pólvora. Folha de São Paulo, Ilustrada, p. E3, edição de quarta-feira, 13 de março de 2002. 
SÃO PAULO (cidade). LEI No 15.951, DE 7 DE JANEIRO DE 2014. Institui Prêmio Zé Renato de apoio à produção e desenvolvimento da atividade teatral para a cidade de São Paulo, e dá outras providências. Disponível em: $<$ http://www.docidadesp.imprensaoficial. com.br/RenderizadorPDF.aspx?ClipID=AN606AHPRCRLOe56QP9VCPH1S47> Acessado em: 5 set. 2018.

SÃO PAULO (cidade). LEI No 14.071, DE 18 DE OUTUBRO DE 2005. Institui o Programa Municipal de Fomento à Dança e dá outras providências. Disponível em: <https:// leismunicipais.com.br/a/sp/s/sao-paulo/lei-ordinaria/2005/1408/14071/lei-ordinaria-n-140712005-institui-o-programa-municipal-de-fomento-a-danca-para-a-cidade-de-sao-paulo-e-daoutras-providencias-2005-10-18-versao-original>. Acessado em: 4 jul. 2018.

SÃO PAULO (cidade). LEI No 13.279, 8 DE JANEIRO DE 2002. Institui o Programa Municipal de Fomento ao Teatro para a Cidade de São Paulo e dá outras providências. Disponível em: <http://www3.prefeitura.sp.gov.br/cadlem/secretarias/negocios_juridicos/ cadlem/integra.asp?alt=09012002L\%20132790000>. Acessado em: 5 jul.2018.

WEISS, Ana. Artistas promovem debate sobre arte e política. O Estado de São Paulo. Caderno 2, p.5, edição de sexta-feira, 7 de maio de 1999.

WEFFORT, Francisco. Entrevista realizada por Fabio Maleronka Ferron e Sergio Cohn no dia 14 de junho em São Paulo. In: TADEI, Roberto \& MILANI, Aloísio (coord.). Produção cultural no Brasil. Projeto realizado pela Casa da Cultura Digital e da Secretaria de Políticas Culturais do Ministério da Cultura, 2010. Disponível em $<\mathrm{https}$ ://valberlucio. wordpress.com/2011/04/11/baixe-as-entrevistas-em-pdf-dos-livro-producao-cultural-nobrasil/>. Acessado em: 7 jul. 2018.

WOO, Chin Tao. Privatização da cultura: a intervenção corporativa nas artes desde 1980. São Paulo: Boitempo, 2006.

Recebido em 28/02/2019.

Aprovado em 29/04/2019. 